\title{
Temporary axillofemoral bypass for reperfusion of an ischemic limb complicating type A dissection
}

\author{
Syed T. Hussain, MD, ${ }^{a}$ Sunita Srivastava, MD, ${ }^{\mathrm{b}}$ and Douglas R. Johnston, MD, ${ }^{\mathrm{a}}$ Cleveland, Ohio
}

\footnotetext{
From the Departments of ${ }^{\mathrm{a}}$ Thoracic and Cardiovascular Surgery and ${ }^{\mathrm{b}}$ Vascular Surgery, Heart and Vascular Institute, Cleveland Clinic, Cleveland, Ohio.

Disclosures: Authors have nothing to disclose with regard to commercial support.

Received for publication Oct 13, 2015; revisions received Nov 10, 2015; accepted for publication Nov 18, 2015 available ahead of print Dec 18, 2015.

Address for reprints: Douglas R. Johnston, MD, Cleveland Clinic, 9500 Euclid Ave, Desk J4-1, Cleveland, OH 44195 (E-mail: johnstd3@ccf.org).

J Thorac Cardiovasc Surg 2016;151:e111-3

$0022-5223 / \$ 36.00$

Copyright (c) 2016 by The American Association for Thoracic Surgery

http://dx.doi.org/10.1016/j.jtcvs.2015.11.030
}

Acute limb ischemia at presentation in acute type A aortic dissection (ATAD) carries significant mortality and morbidity. ${ }^{1-4}$ We describe a novel technique of limb salvage with immediate reperfusion of the ischemic limb by temporary axillofemoral bypass before resternotomy and cardiopulmonary bypass (CPB) in a patient with ATAD who had undergone previous cardiac surgery and had ongoing limb ischemia.

\section{CLINICAL SUMMARY}

A 73-year-old man with a history of esophagectomy 10 years previously and aortic valve replacement 1 year previously was transferred to our institution with a diagnosis of ATAD and pain and paresis of the left leg for 5 hours. A computed tomographic scan showed ATAD involving the supracoronary ascending aorta, arch, and descending aorta, with all the visceral arteries except the left renal artery arising from the true lumen. The aorta was nearly completely occluded at the bifurcation. Left lower extremity ischemia was manifested by motor and sensory loss, a cyanotic left foot, and absence of pulses and Doppler signals, including the femoral signal. On the right side, the patient had no palpable pulse but did have faintly positive femoral and monophasic dorsalis pedis signals.

The patient was taken on an emergency basis to the hybrid operating room. Because he had ongoing limb ischemia for 5 hours as a result of nearly total occlusion of the aortic bifurcation and required resternotomy, we believed that there would be unacceptable delay occasioned by restoration of central aortic perfusion before limb salvage. Because of the nature of aortic occlusion, neither a femorofemoral bypass nor a femorofemoral crossover bypass was possible. Cardiac and vascular surgical teams therefore worked simultaneously to expose the right axillary and left femoral arteries. After heparinization, a short (10 cm long) 8-mm Dacron polyester fabric graft was sewn to the right axillary artery and attached to the Y connector of the arterial limb of the CPB circuit.

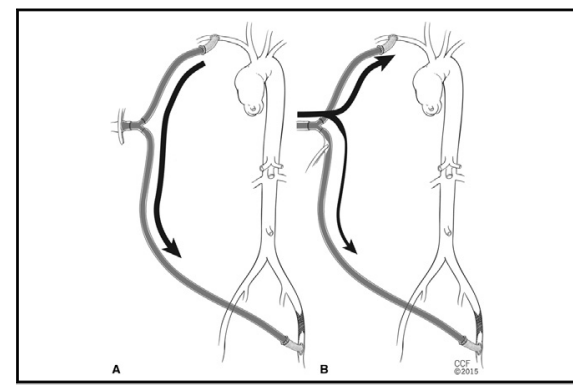

Circuit used for rapid restoration of flow to ischemic limb in acute type A dissection.

\section{Central Message}

Rapid reperfusion with temporary axillofemoral bypass before resternotomy can salvage ischemic limb in acute type A dissection.

See Editorial Commentaries page e113 and $\mathrm{e} 115$.

The left femoral artery had thrombosis of the true lumen, and the dissection ended at the superficial femoral artery. The superficial femoral artery was opened, and after thrombectomy, another short (10 cm long) 8-mm Dacron polyester fabric graft was sewn to the superficial femoral artery distal to where the dissection had terminated. This was connected to the other limb of the arterial $Y$ connector, and the clamps were removed from both grafts, allowing immediate perfusion of left leg through the right axillary artery without initiation of CPB (Figure 1, A). After resternotomy and bicaval cannulation, CPB was initiated, standard repair of ATAD was performed with circulatory arrest, and antegrade left leg perfusion was continued during central circulatory arrest and ascending aorta and hemiarch replacement (Figure 1, B). After $\mathrm{CPB}$, right leg pulses were palpable, and there was a palpable pulse in the left femoral and popliteal arterial course; however, both pulse and Doppler signals were absent in the left foot. A left femoral angiogram demonstrated thrombus in the popliteal artery. After thrombectomy, a completion angiogram showed complete filling of the popliteal arteries and visualization of peroneal and anterior tibial arteries. After protamine reversal of heparinization, a standard 4-compartment fasciotomy was performed, and axillary and femoral grafts were transected close to the anastomosis and the stumps oversewn. The patient's postoperative course was notable for 


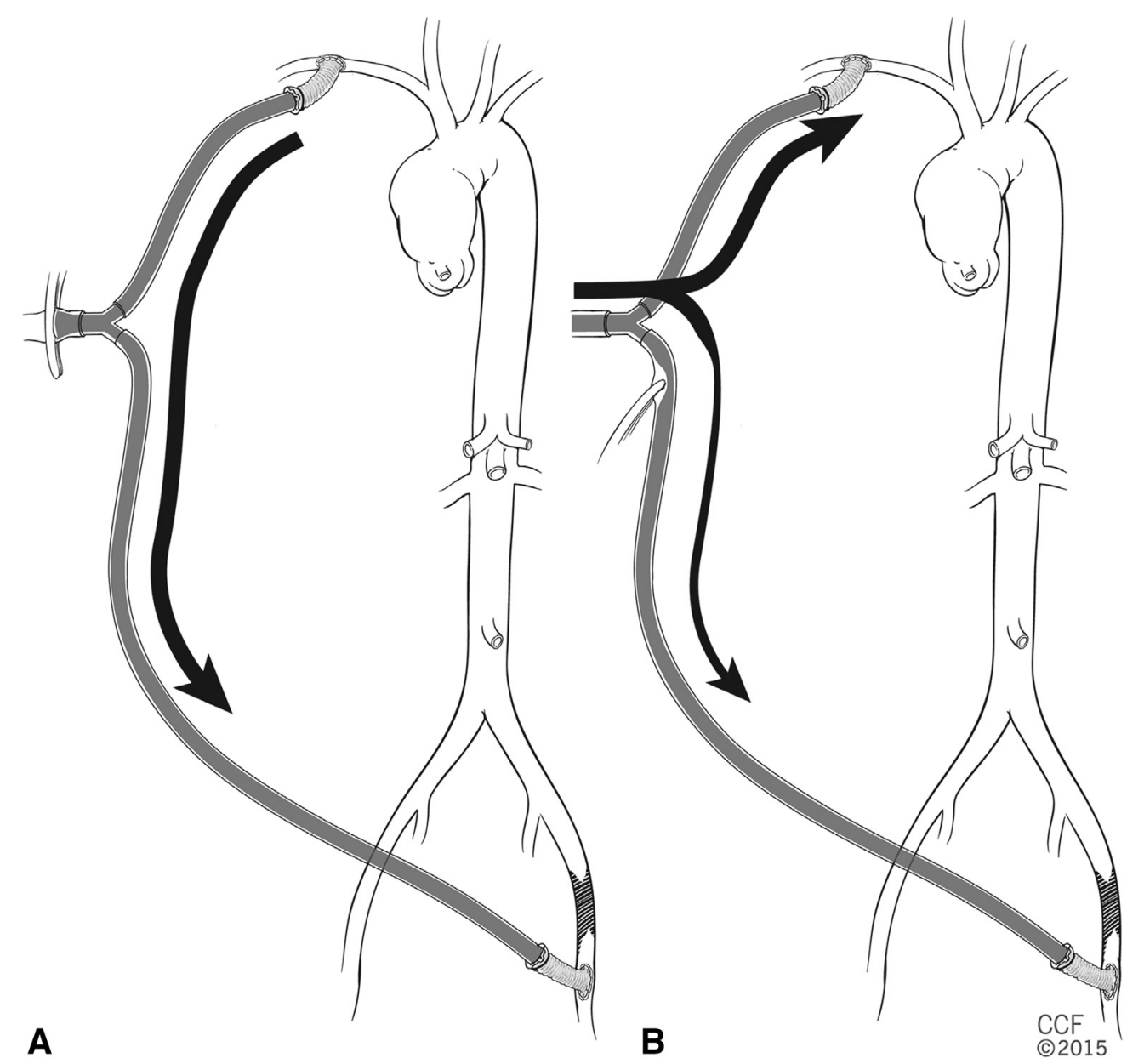

FIGURE 1. The circuit used for immediate reperfusion of an ischemic leg in type A aortic dissection. A, Restoration of flow to the left leg from the right subclavian artery by temporary axillofemoral bypass. B, After the initiation of cardiopulmonary bypass, the pump flow to the left leg was regulated by application of a partial clamp to the lower limb graft. Note that the grafts sewn to the axillary and left femoral arteries were short (about $10 \mathrm{~cm}$ ) in length and connected by straight connectors to both limbs of the arterial inflow from the cardiopulmonary bypass circuit.

rhabdomyolysis (myoglobin $>30,000 \mathrm{ng} / \mathrm{mL}$ ), elevated creatine kinase (>17,000 units/L), and nonoliguric renal failure (creatinine level $5.46 \mathrm{mg} / \mathrm{dL}$ ), which recovered without dialysis. The patient's lower extremity neurologic function gradually improved, and he had no tissue loss in his left leg. The patient was discharged to a rehabilitation facility after 3 weeks, with vacuum dressing of the fasciotomy wound and a plan for delayed wound closure.

\section{DISCUSSION}

The ideal means of restoring end-organ perfusion in ATAD is rapid triage to the operating room and reestablishment of flow within the true lumen. Rapid restoration of flow in the true lumen can alleviate malperfusion syndromes in $33 \%$ to $92 \%$ of patients. ${ }^{1,4}$ Open techniques available to alleviate ongoing limb ischemia include femorofemoral crossover bypass for unilateral involvement, axillobifemoral bypass for bilateral involvement, and femorofemoral bypass if the dissection extends into the femoral bifurcation. ${ }^{4}$

Garret and Wolf ${ }^{5}$ reported the successful restoration of immediate reperfusion of lower extremities through an axillobifemoral graft in 2 patients with ATAD and limb-threatening lower-extremity ischemia. They restored the flow to the leg by connecting the bifemoral graft to the arterial circuit of CPB at the initiation of bypass. Because of prolonged limb ischemia and the need for resternotomy in our case, we modified this technique to start the axillofemoral bypass by connecting the grafts from axillary and femoral arteries to the $\mathrm{Y}$ connector on the arterial limb of the CPB circuit, thus allowing immediate reperfusion of the threatened limb before resternotomy and initiation of CPB. This required no extra time, because we routinely use axillary cannulation with a side graft for ATAD, and another team worked simultaneously on the groin for femoral grafting. 
This strategy of rapid restoration of flow to the ischemic limb with a temporary axillofemoral graft is a simple and potentially beneficial method for limb salvage in ATAD complicated by factors such as prolonged ischemia at presentation or previous sternotomy.

\section{References}

1. Geirsson A, Szeto W, Pochettino A, Mcgarvey ML, Keane MG, Woo YJ, et al. Significance of malperfusion syndrome prior to contemporary surgical repair for acute type A dissection: outcomes and need for additional revascularizations. Eur J Cardiothoracic Surg. 2007;32:255-62.
2. Patel HJ, Williams DM, Dasika NL, Suzuki Y, Deeb GM. Operative delay for peripheral malperfusion syndrome in acute type A aortic dissection: a longterm analysis. J Thorac Cardiovasc Surg. 2008;135:1288-95; discussion 1295-6.

3. Girdauskas E, Kuntze T, Borger MA, Falk V, Mohr FW. Surgical risk of preoperative malperfusion in acute type A aortic dissection. J Thorac Cardiovasc Surg. 2009;138:1363-9.

4. Sandridge L, Kern JA. Acute descending aortic dissections: management of visceral, spinal cord and extremity malperfusion. Semin Thorac Cardiovasc Surg. 2005; 17:256-61.

5. Garrett HE Jr, Wolf BA. Management of acute infrarenal aortic infrarenal aortic occlusion secondary to type A dissection. Ann Thorac Surg. 2006;81: $1500-2$.

\title{
EDITORIAL COMMENTARY
}

\section{Early reperfusion for acute type A dissection complicated with distal malperfusion}

\author{
Arminder S. Jassar, MBBS, and Wilson Y. Szeto, MD
}

\footnotetext{
From the Division of Cardiovascular Surgery, University of Pennsylvania, Philadelphia, Pa. Disclosures: Authors have nothing to disclose with regard to commercial support.

Received for publication Jan 31, 2016; accepted for publication Feb 2, 2016; available ahead of print March 5, 2016.

Address for reprints: Wilson Y. Szeto, MD, Associate Professor of Surgery, University of Pennsylvania School of

Medicine, Chief of Cardiovascular Surgery at Penn Presbyterian Medical Center, 51 N 39th St, Heart and

Vascular Pavilion, Suite 2A, Philadelphia, PA 19104 (E-mail: wilson.szeto@uphs.upenn.edu).

J Thorac Cardiovasc Surg 2016;151:e113-4

0022-5223/\$36.00

Copyright $(2016$ by The American Association for Thoracic Surgery

http://dx.doi.org/10.1016/j.jtcvs.2016.02.004
}

Acute type A dissection remains a challenging clinical scenario. Prevalence of previous cardiac surgery in patients presenting with acute type A dissection is approximately $9 \%$ to $16 \%$ and has been shown to worsen both in-hospital and long-term mortality. ${ }^{1,2}$ Similarly, patients with acute type A dissection who present with malperfusion have increased perioperative and long-term mortality. $^{3-5}$ This has led several groups to advocate early reperfusion with either thoracic endovascular aortic repair (Figure 1) or percutaneous fenestration of the dissection flap to restore true-lumen blood flow and subsequent performance of the proximal repair of type A dissection in a delayed fashion once patient has been stabilized. ${ }^{6,7}$ This approach of delayed type A dissection repair may be even more applicable in the setting of a reoperation, since these patients have a lower probability of tamponade and frank rupture than do patients with type $\mathrm{A}$ dissection in a nonreoperative setting because of adhesions from the previous operations. ${ }^{1}$

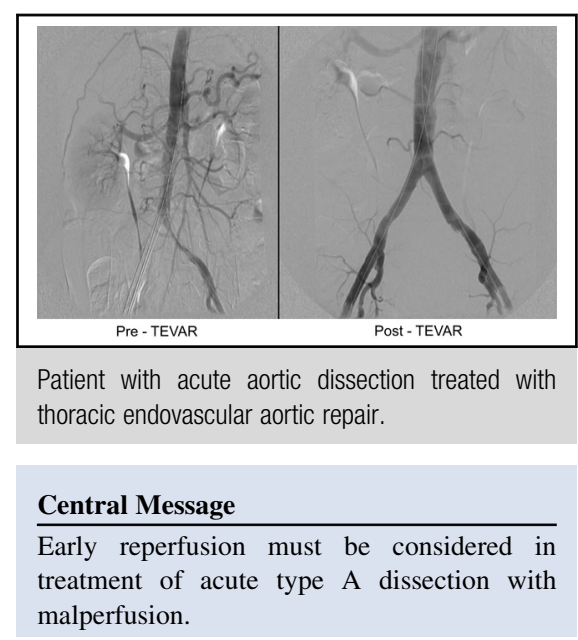

See Article page e111.

In this report, Hussain and colleagues ${ }^{8}$ used a creative strategy to reperfuse the lower extremity as resternotomy and dissection were being performed. The procedure involves an extra-anatomic circuit to provide early perfusion to the malperfused distal organ bed while at the same time providing arterial inflow for cardiopulmonary bypass and cerebral perfusion during circulatory arrest. Unfortunately, the leg remained ischemic, as discovered by the completion angiogram performed after the dissection repair. It is conceivable that definitive treatment of the lower extremity malperfusion with an 